\title{
Análise da Atitude dos Turistas com Relação ao Desenvolvimento da Energia Eólica no Litoral Cearense, Brasil
}

\author{
Analysis of the Tourists' Attitude towards the Power Wind Development in Ceará \\ Cost, Brazil
}

Rogério César Pereira de Araújo (ARAÚJO, R. C. P. de)

\begin{abstract}
RESUMO - Neste trabalho se analisa a atitude dos turistas domésticos com relação ao desenvolvimento da energia eólica na Zona Costeira do Estado do Ceará (Brasil). Para isto, modelos de formação de atitude dos turistas são propostos com o intuito de testar a significância das variáveis que influenciam sua posição em apoiar o desenvolvimento da energia eólica. Dados primários foram coletados a partir da aplicação de um questionário a uma amostra de 117 turistas que visitavam dois importantes destinos turísticos do Ceará, a praia de Canoa Quebrada e a praia de Jericoacoara. Utilizando um modelo logit linear em suas variáveis explicativas, pôde-se constatar que a posição favorável dos turistas domésticos com relação ao desenvolvimento da energia eólica na zona costeira é influenciada significativamente pelas variáveis demográficas e pelos fatores que descrevem sua atitude política e percepção sobre a magnitude dos impactos ambientais causados pelas usinas eólicas.
\end{abstract}

Palavras chave: Energia eólica; Turismo; Atitude e comportamento ambiental; Externalidade visual; Ceará.

ABSTRACT - This study analyzes the domestic tourists' attitudes towards the power wind development in Ceará Cost, Brazil. For that, models of tourists' attitude formation are proposed aiming to test the significance of the variables which affect their choice in supporting the power wind development. It was used primary data gathered by questionnaire application to 117 tourists that were visiting the two most important touristic destinations in Ceara, Canoa Quebrada beach and the Jericoacoara beach. Using a linear logit model, it was concluded that the domestic tourist position in favor of the wind power development in the coastal zone is significantly driven by the demographic variables and the set of attitudes describing their political attitudes and their perception on the magnitude of the environmental impacts caused by the wind farms.

Key Words: Wind power; Environmental attitude and behavior; Visual externality; Ceará.

\footnotetext{
* Formação: Graduação em Engenharia Agronômica e Mestrado em Economia Rural pela Universidade Federal do Ceará (UFC); PhD em Economia Agrícola pela University of Illinois at Urbana-Champaign (EUA); Pós-Doutorado no Departamento de Economia Agrícola e de Recursos na Colorado State University (EUA). Atividade Profissional: Professor Associado II do Departamento de Economia Agrícola (UFC). Endereço físico para correspondência: Departamento de Economia Agrícola, Centro de Ciências Agrárias/UFC, CP 6017, Campus do Pici. CEP: 60.455-970 - Fortaleza - Ceará (Brasil). Telefone: (85) 3366-9718. Fax: (85) 3366-9716. E-mail: rcpa@ufc.br
} 


\section{INTRODUÇÃO}

Na última década, acompanhando a tendência mundial, a geração de energia eólica vem crescendo de forma acelerada no Brasil, o qual possui um potencial eólico que pode chegar até a $143 \mathrm{GW}$ (AMARANTE et al., 2001). No Plano Decanal de Expansão de Energia 2020 se fez uma estimativa que até o final de 2016 a capacidade instalada de energia eólica no Brasil alcançaria 8,1 GW, mais de cinco vezes a capacidade instalada em 2011 (1,5 GW) (EPE, 2011; SIMAS; PACCA, 2013b).

A maior parte desse potencial eólico encontra-se na região Nordeste, com uma estimativa de $75 \mathrm{GW}$ na altura de 50 metros, correspondendo a 52,4\% do máximo potencial brasileiro (ANEEL, 2008). Somente o estado do Ceará teria uma capacidade estimada de $25 \mathrm{GW}$, principalmente no litoral, que corresponderia a $17,5 \%$ da capacidade nacional e 33,3\% da capacidade do Nordeste.

A energia eólica reúne uma série de aspectos favoráveis à sustentabilidade do setor energético por ser um recurso renovável, de baixa emissão de carbono, e de fluxo inesgotável e perene (ANEEL, 2008). Dentre suas vantagens, destacam-se sua contribuição para a redução das emissões de gases de efeito estufa, mitigando assim os efeitos negativos das mudanças climáticas e do aquecimento global (SIMAS; PACCA, 2013a). Além disso, a energia eólica reduz a demanda pela construção de usinas hidroelétricas, preservando a biodiversidade e os recursos naturais das comunidades ribeirinhas (ALVES, 2010).

A geração de energia eólica também tem sido apontada como responsável por uma variedade de impactos ambientais negativos, sendo os principais a poluição sonora causada pelos ruídos dos rotores; a poluição visual provocada pelo agrupamento de torres e aerogeradores que altera a paisagem natural; o desvio de rotas migratórias de animais voadores; e a mortalidade de pássaros por colisão nas pás (SNYDER; KAISER, 2009; ANEEL, 2008). Esses impactos são considerados de baixa magnitude quando comparados aos sistemas de geração de eletricidade convencionais (NASCIMENTO et al., 2012).

Os principais argumentos usados pelos grupos de interesse que se opõem ao desenvolvimento da energia eólica têm sido o impacto sobre a estética da paisagem e o turismo (KARYDIS, 2013). Ambos decorrentes da instalação de turbinas eólicas que 
levaria à alteração da paisagem natural, perda da beleza cênica e redução do seu valor estético. Por ter seu valor estético diminuído, as atividades que estão associadas a este serviço podem sofrer impactos negativos, como é o caso do turismo.

Na região Nordeste, o turismo constitui-se em um setor econômico importante para o desenvolvimento e redução das desigualdades regionais. Em particular, no estado do Ceará, o setor do turismo teve uma participação de 11,8\% no PIB estadual, em 2005 (CEARÁ, 2006). De acordo com a Secretaria do Turismo do Ceará (SETUR-CE), os turistas tiveram uma maior demanda pelo segmento "sol e praia", sendo as praias de Cumbuco $(16,1 \%)$, Canoa Quebrada $(14,2 \%)$ e Jericoacoara $(9,5 \%)$ aquelas mais visitadas, segundo dados de 2008 (CEARÁ, 2009). Ainda segunda a SETUR-CE, para $46 \%$ dos turistas, sua principal motivação era por passeio, tendo $87,7 \%$ deles indicado os atrativos naturais como o principal estímulo, dentre eles os campos de dunas litorâneos.

No Nordeste do Brasil, as usinas eólicas estão sendo instaladas ao longo do litoral, principalmente em áreas de dunas pelo fato destas áreas possuírem maior potencial eólico. O campo de dunas, além de ser uma feição característica do ecossistema costeiro, também é um atrativo turístico importante em função da beleza cênica e experiência recreativa que oferece, por exemplo, passeios de bugre nas dunas.

Desta forma, a alteração da paisagem costeira poderia representar uma depreciação deste ecossistema, possibilitando ainda resultar em mudanças nas preferências dos turistas por destinos de praia (MOURA-FÉ; PINHEIRO, 2013). Como resultado, o segmento do turismo de "sol e praia" poderia ser afetado negativamente pela depreciação do capital paisagístico natural do litoral.

Ladenburg (2010) afirma que aqueles que visitam a praia e/ou fazem uso da zona costeira para atividades de recreação, em grande parte, são os que sofrerão os impactos potenciais dos parques eólicos. Portanto, investigar as atitudes dos usuários da zona costeira é uma forma indireta de dar uma ideia dos potenciais impactos desta política na sociedade. Em outros países, as atitudes da população com relação ao desenvolvimento da energia eólica foram investigadas por Ek (2005), Jones e Eiser (2010), Krohn e Damborg (1999) e Ladenburga e Möllerb (2011).

Esta pesquisa tem seu foco na análise das atitudes, comportamentos e percepção dos turistas domésticos relacionados com o apoio ou não ao desenvolvimento da energia 
eólica no litoral cearense. Assim, pretende-se saber a posição do turista doméstico com relação a esta política e identificar seus fatores determinantes. A literatura tem mostrado que as variáveis demográficas, socioeconômicas, geográficas e de percepção e crença são importantes para explicar a atitude com relação à energia eólica (LADENBURG, 2010; LADENBURG, 2008).

Nesta pesquisa objetiva-se estimar um modelo de formação de atitude dos turistas domésticos com relação ao desenvolvimento da energia eólica incluindo-se como variáveis explicativas, além de variáveis sugeridas pela literatura, aquelas que descrevem a percepção de impactos da energia eólica e os componentes da posição política do turista doméstico.

Para isto, foram formuladas questões estruturadas para levantar informações sobre as características demográficas, a experiência turística, a percepção dos impactos socioambientais das usinas eólicas e as atitudes dos turistas relacionadas ao desenvolvimento da energia eólica. Com estes dados, teve-se como identificar quais seriam as variáveis que se mostravam significativas em explicar as atitudes do turista doméstico e prever a probabilidade de seu posicionamento, a favor ou contra, com relação ao desenvolvimento da energia eólica no estado do Ceará.

Desta forma, esta pesquisa assume sua relevância por gerar informação para subsidiar o debate em torno dos impactos da energia eólica na zona costeira, particularmente sobre o setor do turismo. Espera-se também compreender como os usuários da praia reagem às alterações da paisagem costeira. E, finalmente, auxiliar no planejamento da política de energia eólica a fim de minimizar seus impactos sobre o turismo de "sol e praia".

Este artigo é composto de três seções, além da seção introdutória. A seguir são apresentados o método de formação de atitude e os procedimentos metodológicos empregados na pesquisa. Depois disto, os resultados são apresentados e discutidos, enfatizando a descrição do perfil dos respondentes e a análise dos modelos propostos e variáveis consideradas. Por último, constam as conclusões e sugestões. 


\section{MODELO DE FORMAÇÃO DE ATITUDE}

Tomando como base Ladenburga e Möllerb (2011), neste artigo se propõe um modelo de formação de atitude individual com relação ao desenvolvimento da energia eólica.

Neste modelo, a atitude ou posição do indivíduo $i$ (favorável ou contra) a uma política é expressa pela variável latente não observada $q_{i}{ }^{*}$. Um indivíduo é favorável à política se $q_{i}{ }^{*} \geq t$ e contrário se $q_{i}{ }^{*}<t$. O parâmetro $t$ representa a noção de valor que o indivíduo atribui à política e que permite distinguir sua posição positiva (favorável) da posição negativa (contrária), não sendo permitida posição de neutralidade sobre a questão.

Pressupõe-se que $q_{i}{ }^{*}$ é determinado por um conjunto de variáveis observáveis e não observáveis que descrevem as características demográficas e comportamentais (valores, percepções e ações) do indivíduo. Matematicamente, o modelo genérico de formação de atitude é expresso como:

$$
q_{i}^{*}=f\left(X_{i}, Y_{i}, Z_{i}, W_{i}\right)
$$

Onde: $q_{i}{ }^{*}$ é uma variável dicotômica que assume o valor 1 se o indivíduo $i$ for favorável à política e 0 , se contrário; e $X_{i}, Y_{i}, Z_{i}$ e $W_{i}$ são vetores que descrevem, respectivamente, as características demográficas, a experiência turística, a percepção dos impactos socioambientais e as atitudes do indivíduo $i$ com relação à política.

Utiliza-se o modelo logit (ML) para ajustar os dados por ser este a abordagem mais amplamente aplicada quando a variável dependente é qualitativa. O modelo logit tem como objetivo estimar o efeito de mudanças nas variáveis explicativas sobre o logaritmo natural da razão das probabilidades dos eventos $\left(\ln \left[q_{i} /\left(1-q_{i}\right)\right]\right)$, sendo $q_{i}$ a probabilidade de ser favorável e $\left(1-q_{i}\right)$ a probabilidade de ser contrário à política. As variáveis explicativas são distribuídas em quatro categorias: características demográficas $\left(\boldsymbol{X}_{\boldsymbol{i}}\right)$, variáveis comportamentais $\left(\boldsymbol{Y}_{\boldsymbol{i}}\right)$, percepção dos impactos ambientais $\left(\boldsymbol{Z}_{i}\right)$ e as atitudes individuais com relação à política $\left(\boldsymbol{W}_{\boldsymbol{i}}\right)$; às quais estão associados aos seus respectivos coeficientes $\boldsymbol{\beta}, \boldsymbol{\varphi}, \boldsymbol{\mu}$ and $\boldsymbol{\delta}$. O termo constante e o erro aleatório são expressos por $\alpha$ e $\boldsymbol{\varepsilon}_{\boldsymbol{i}}$. Matematicamente, o modelo logístico empírico é expresso por: 


$$
\ln \left\lfloor\frac{q_{i}}{\left(1-q_{i}\right)}\right\rfloor=\alpha+\beta X_{i}+\varphi Y_{i}+\mu Z_{i}+\delta W_{i}+\epsilon_{i}
$$

As variáveis utilizadas no modelo logístico são apresentadas na Tabela 1, acompanhadas de sua definição e codificação. Ao todo, são consideradas 28 variáveis explicativas: 10 variáveis demográficas $\left(\boldsymbol{X}_{\boldsymbol{i}}\right) ; 5$ variáveis que descrevem a experiência turística $\left(\boldsymbol{Y}_{\boldsymbol{i}}\right) ; 7$ variáveis que descrevem a atitude política $\left(\boldsymbol{W}_{\boldsymbol{i}}\right.$ e IDEE); e 6 descritores da percepção de impactos socioambientais $\left(\boldsymbol{Z}_{\boldsymbol{i}}\right.$ e $\left.I I S A\right)$. Na tabela, as variáveis são apresentadas de acordo com sua classificação em contínua, discreta, binária (dummy), ordinal e intervalo escalar.

TABELA 1 - DEFINIÇÃO DAS VARIÁVEIS UTILIZADAS NO MODELO LOGÍSTICO DE FORMAÇÃO DE ATITUDES DOS TURISTAS COM RELAÇÃO AO DESENVOLVIMENTO DA ENERGIA EÓLICA NO LITORAL CEARENSE

\begin{tabular}{|c|c|c|}
\hline Variáveis & Definição & Código \\
\hline$q_{i}$ & $\begin{array}{l}\text { Posição do respondente sobre o desenvolvimento da } \\
\text { energia eólica na Zona Costeira }\end{array}$ & $\begin{array}{l}\text { Binária: } 1 \text { se a favor do } \\
\text { desenvolvimento, caso contrário } 0\end{array}$ \\
\hline XIDADE & Idade do respondente & Contínua \\
\hline XGENERO & Gênero & $\begin{array}{l}\text { Binária: } 1 \text { se for feminino; } 0 \text { se for } \\
\text { masculino. }\end{array}$ \\
\hline XESTCIV & Estado civil & $\begin{array}{l}\text { Binária: } 1 \text { se for solteiro; } 0 \text { se for } \\
\text { casado, união estável, separado, } \\
\text { divorciado ou viúvo. }\end{array}$ \\
\hline XNFILHOS & Nenhum filho & $\begin{array}{l}\text { Binária: } 1 \text { se não tiver filhos; } 0 \text { se dois } \\
\text { ou mais filhos. }\end{array}$ \\
\hline XFILIAMB & Filiado ou não a organização ambientalista & $\begin{array}{l}\text { Binária: } 1 \text { se for filiado, caso contrario } \\
0 .\end{array}$ \\
\hline XRENDA1 & Renda pessoal mensal inferior a $\mathrm{R} \$ 2.400$ & $\begin{array}{l}\text { Binária: } 1 \text { se receber menos de } \mathrm{R} \$ \\
2.400 ; 0 \text {, caso contrário. }\end{array}$ \\
\hline XRENDA2 & Renda pessoal mensal entre $\mathrm{R} \$ 2.400$ e $\mathrm{R} \$ 8.000$ & $\begin{array}{l}\text { Binária: } 1 \text { se receber entre } \mathrm{R} \$ 2.400 \mathrm{e} \\
\mathrm{R} \$ 8.000 ; 0 \text {, caso contrário. }\end{array}$ \\
\hline XRENDA3 & Renda pessoal mensal superior a $\mathrm{R} \$ 8.000$ & $\begin{array}{l}\text { Binária: } 1 \text { se receber mais de } \mathrm{R} \$ \\
8.000 ; 0 \text {, caso contrário. (omitida) }\end{array}$ \\
\hline XESCAMF & $\begin{array}{l}\text { Escolaridade ao nível Fundamental ou Médio, } \\
\text { incompleto ou completo, ou analfabeto (AFM) }\end{array}$ & $\begin{array}{l}\text { Binária: } 1 \text { se escolaridade for AMF; } 0 \text {, } \\
\text { caso contrário. }\end{array}$ \\
\hline$X E S C S P G$ & $\begin{array}{l}\text { Escolaridade ao nível Superior ou Pós-Graduação, } \\
\text { incompleto ou completo (SPG) }\end{array}$ & $\begin{array}{l}\text { Binária: } 1 \text { se escolaridade for SPG; } 0 \text {, } \\
\text { caso contrário. (omitida). }\end{array}$ \\
\hline YFQPRAIA & Vai à praia raramente ou de vez em quando & $\begin{array}{l}\text { Binária: } 1 \text { se vai a praia raramente ou } \\
\text { de vez em quando; } 0 \text { se for com } \\
\text { frequência ou todo dia. }\end{array}$ \\
\hline YPERM12 & Permanece na praia 1 ou 2 dias & $\begin{array}{l}\text { Binária: } 1 \text { se permanecer na praia } 1 \text { ou } \\
2 \text { dias; } 0 \text {, caso contrário. }\end{array}$ \\
\hline YPERM35 & Permanece na praia de 3 a 5 dias & $\begin{array}{l}\text { Binária: } 1 \text { se permanecer na praia de } 3 \\
\text { a } 5 \text { dias; } 0 \text {, caso contrário. }\end{array}$ \\
\hline
\end{tabular}




\begin{tabular}{|c|c|c|}
\hline YPERM6M & Permanece na praia 6 ou mais dias & $\begin{array}{l}\text { Binária: } 1 \text { se permanecer na praia } 6 \text { ou } \\
\text { mais dias; } 0 \text {, caso contrário. (omitida) }\end{array}$ \\
\hline YPRAIA & Canoa Quebrada ou Jericoacoara & $\begin{array}{l}\text { Binária: } 1 \text { se for a praia de Canoa } \\
\text { Quebrada; } 0 \text { se for a praia de } \\
\text { Jericoacoara. }\end{array}$ \\
\hline WENGLIMPA & Usina eólica é fonte de energia limpa $(\mathrm{k}=1)$ & \multirow{5}{*}{$\begin{array}{l}\text { Ordinal: } \\
1 \text { = Concordo Fortemente; } \\
2 \text { = Concordo; } \\
3 \text { = Discordo } \\
4 \text { = Discordo Fortemente. }\end{array}$} \\
\hline WPSGEOLIC & Prefiro paisagem com usina eólica $(\mathrm{k}=2)$ & \\
\hline WEOLICAT & Usina eólica é atrativo turístico $(\mathrm{k}=3)$ & \\
\hline WPREFEO & $\begin{array}{l}\text { Prefiro perder paisagem do que ficar sem energia } \\
\text { elétrica }(k=4)\end{array}$ & \\
\hline WCOMPCOM & $\begin{array}{l}\text { Comunidades afetadas pelas usinas eólicas não } \\
\text { devem ser compensadas }(\mathrm{k}=5)\end{array}$ & \\
\hline ZOBSTPGS & Obstrução da paisagem $(\mathrm{j}=1)$ & \multirow{6}{*}{$\begin{array}{l}\text { Escalar: } \\
1 \text { = Desprezível } \\
2 \text { = Baixo; } \\
3 \text { = Moderado; } \\
4 \text { = Elevado; } \\
5 \text { = Severo }\end{array}$} \\
\hline ZPOLVIS & Poluição visual ( $\mathrm{j}=2$ ) & \\
\hline ZPOLSON & Poluição sonora $(\mathrm{j}=3)$ & \\
\hline ZMTACIDENT & Morte acidental de pássaros por colisão $(\mathrm{j}=4)$ & \\
\hline ZMIGDUNA & Migração das dunas $(\mathrm{j}=5)$ & \\
\hline ZRESTACES & Restrição de acesso às comunidades $(\mathrm{j}=6)$ & \\
\hline$I D E E$ & Índice Médio de Desenvolvimento da Energia Eólica & Contínua. \\
\hline IISA & $\begin{array}{l}\text { Índice Médio de Percepção de Impacto } \\
\text { Socioambiental }\end{array}$ & Contínua. \\
\hline
\end{tabular}

Duas variáveis são consideradas na forma de índice composto: Índice Médio de Desenvolvimento da Energia Eólica (IDEE); e o Índice Médio de Percepção de Impacto Socioambiental (IISA). Estes índices são utilizados em substituição aos vetores de atitude política e de percepção de impacto socioambiental no modelo logit. Os índices são incluídos nesta análise com o intuito de verificar se a posição política do turista com relação à política de energia eólica é sensível à atitude política e percepção dos impactos mensurados na forma de índices compostos construídos a partir dos fatores que os descrevem.

O Índice Médio de Percepção de Impacto Socioambiental do indivíduo $i\left(I D E E_{i}\right)$ representa a atitude geral do indivíduo com relação ao desenvolvimento da energia eólica, calculado pela média aritmética dos escores atribuídos pelo indivíduo $i$ aos fatores de atitude $A_{k}$, sendo o número total de fatores $(K)$ igual a cinco, como mostrado pela Equação 3.

$$
I D E E_{i}=\frac{1}{K} \sum_{k=1}^{k=K} A_{k}
$$


O Índice Médio de Percepção de Impacto Socioambiental do indivíduo $i\left(I I S A_{i}\right)$ expressa o nível geral dos impactos socioambientais percebidos pelo indivíduo, calculado pela média aritmética dos escores atribuídos pelo indivíduo $i$ aos fatores de impacto $I_{j}$, sendo o número total de impactos $(J)$ igual a seis, como mostrado pela Equação 4.

$$
I I S A_{i}=\frac{1}{J} \sum_{j=1}^{j=J} I_{j}
$$

O modelo logit é estimado por meio do método de Máxima Verossimilhança (WOOLDRIDGE, 2006). Uma vez estimado o modelo logístico, o valor do coeficiente de uma variável mede o quanto o logaritmo natural da razão das chances dos eventos varia em função da mudança no valor da variável considerada (DEMARIS, 1992).

A estratégia empírica da análise de regressão consiste em especificar seis modelos logit, cada um com a finalidade de testar um conjunto específico de variáveis explicativas. Inicialmente, especifica-se o modelo completo (ML1), ou seja, o modelo no qual todas as categorias de variáveis explicativas são incluídas.

Em seguida, cinco modelos reduzidos são estimados excluindo sistematicamente as categorias de variáveis explicativas (uma categoria por vez): ML2 exclui apenas as variáveis demográficas; ML3 exclui apenas as variáveis que descrevem a experiência de recreação; ML4 exclui apenas os descritores da atitude política; ML5 exclui apenas os descritores de percepção dos impactos socioambientais; e ML6 substitui os descritores de atitude política e de percepção dos impactos ambientais por seus respectivos índices compostos. Os descritores de atitude política e de percepção dos impactos e seus respectivos índices não podem fazer parte do mesmo modelo pelo fato de resultar em multicolinearidade, ou seja, estabelecer uma relação perfeitamente linear entre os descritores e o índice calculado a partir deles (GUJARATI, 2003).

Ao todo são estimados e avaliados seis modelos, um modelo completo e cinco modelos em formato reduzido, quanto ao seu desempenho em ajustar os dados. Além do valor do logaritmo de máxima verossimilhança, o grau de ajustamento dos modelos é aferido também pelo pseudo $\mathrm{R}^{2}$ e o $\mathrm{R}^{2}$ de contagem (GUJARATI, 2003). Assim como o $\mathrm{R}^{2}$ típico, o pseudo $\mathrm{R}^{2}$ varia no intervalo de 0 a 1 . Já o $\mathrm{R}^{2}$ de contagem é obtido pela 
razão entre o número correto de previsões e o número total de observações e mede o percentual de probabilidades corretamente previstas.

Gujarati (2003) salienta que em modelos de variável dependente na forma de resposta binária, o grau de ajustamento do modelo é de importância secundária, devendo-se dar maior atenção aos sinais esperados dos coeficientes da regressão e sua significância prática e/ou estatística. Desta forma, a significância estatística dos coeficientes é testada com base na estatística Z (distribuição normal padronizada). A significância dos grupos de variáveis excluídas é testada usando o Teste da Razão de Verossimilhança (TRV).

\section{COLETA DE DADOS}

Nesta seção, apresenta-se a estratégia de amostragem da pesquisa, onde se definiu a área de estudo, a população amostral e a amostra de respondentes. Em seguida, descreve-se o questionário usado para a coleta de dados.

\subsection{ESTRATÉGIA AMOSTRAL}

Esta pesquisa foi conduzida a partir de uma amostra de turistas e visitantes domésticos das praias de Canoa Quebrada, no município de Aracati (litoral Leste), e de Jericoacoara, no município de Jijoca de Jericoacoara (litoral Oeste). Estas praias estão localizadas, respectivamente, a cerca de $170 \mathrm{Km}$ e a $300 \mathrm{Km}$ da capital, Fortaleza, incluindo-se entre as três praias mais preferidas pelos turistas no Ceará (SOUZA NETE, 2011; BRASIL, 2010; SETUR, 2009).

Esses dois destinos permitiram reunir uma amostra de turistas que escolheram visitar uma praia cuja paisagem foi marcantemente alterada pelas usinas eólicas (Canoa Quebrada) com aqueles que escolheram visitar uma praia cuja paisagem ainda se encontra praticamente inalterada (Jericoacoara). Segundo o Banco de Informação de Geração (BIG) da ANEEL, no município de Aracati, encontram-se em operação seis usinas eólicas (Eólica Canoa Quebrada, Lagoa do Mato, Parque Eólico Enacel, Canoa Quebrada, Bons Ventos e Quixadá), totalizando 177,7 MW (ANEEL, 2014). 
A população amostral foi formada pelos turistas domésticos que visitam as praias localizadas no litoral cearense. Para esta pesquisa, os turistas domésticos de interesse foram os brasileiros que se deslocam de sua residência e permanecem nas praias de Canoa Quebrada e Jericoacoara por pelo menos um dia (24 horas), podendo ou não pernoitar na praia.

Nesta pesquisa, buscou-se coletar uma amostra aleatória dos turistas domésticos das duas praias em estudo. Para isto, foram utilizadas conjuntamente duas abordagens: (i) amostragem por julgamento dos destinos de praia (abordagem não probabilística); e (ii) amostragem sistemática dos turistas nas praias selecionadas (abordagem probabilística).

A escolha da abordagem não probabilística deve-se ao fato da população amostral teoricamente ser grande e não se dispor das informações necessárias para efetuar uma amostragem aleatória simples ou ainda de recursos humanos e financeiros suficientes para tal tarefa.

A amostragem sistemática aos turistas em cada praia foi feita selecionando um respondente a cada três usuários encontrados à medida que o anotador se deslocava de um extremo a outro da praia. Ao abordar o turista, o anotador perguntava se ele ou ela gostaria de participar voluntariamente da pesquisa.

Foi utilizado um único questionário para a coleta de dados nas duas praias selecionadas. Os questionários foram aplicados em dois finais de semanas consecutivos, tendo-se trabalhado um final de semana em cada praia. Em Canoa Quebrada, os questionários foram aplicados nos dias 29 e 30 de outubro de 2011 e, em Jericoacoara, nos dias 5 e 6 de novembro de 2011.

Os respondentes foram abordados na faixa de praia e também nas ruas, passarelas e calçadões que dão acesso à praia. Os questionários foram aplicados por alunos de pós-graduação treinados para realizar pesquisa de valoração econômica ambiental. A taxa de rejeição dos respondentes ao questionário foi da ordem de $10 \%$, ou seja, de cada dez pessoas convidadas, uma preferiu não participar da pesquisa.

Foram coletados 117 questionários válidos, sendo 65 (55,5\%) questionários em Canoa Quebrada e $52(44,4 \%)$ questionários em Jericoacoara. O fato de se ter uma amostra formada por pessoas que se dispuseram a participar da pesquisa pode ter gerado uma amostra enviesada, denominada de viés de auto-seleção (self selection bias). 
Porém, pelo fato de ter havido baixa taxa de rejeição (10\%), acredita-se que tal viés não tenha afetado adversamente os resultados.

\subsection{QUESTIONÁRIO}

Os dados são de natureza primária, tendo sido coletados através de aplicação direta (face-a-face) de questionário formado por questões estruturadas (questões fechadas). O questionário foi subdividido em três seções. A primeira seção coleta informações sobre a identificação do respondente: nome, local de residência, principal meio de transporte utilizado na viagem, número de dias de permanência na praia, e número de pessoas acompanhantes.

A segunda seção coleta informações sobre a atitude, percepção e opinião do respondente com relação ao desenvolvimento da energia eólica. A atitude do respondente é mensurada através de uma escala de quatro pontos do tipo Likert: 1 Discordo Fortemente; 2 - Discordo; 3 -Concordo; e 4 -Concordo Fortemente. A percepção dos turistas quanto aos impactos socioambientais causados pelas usinas eólicas é aferida utilizando uma escala de 5 pontos: 1 - Desprezível; 2 - Baixo; 3 Moderado; 4 - Elevado; e 5 - Severo. Também é registrada a opinião do turista quanto à localização das usinas e as políticas direcionadas ao desenvolvimento da energia eólica.

Na terceira e última seção foram coletadas as características demográficas dos respondentes, tais como idade, sexo, estado civil, número de filhos, principal ocupação, renda pessoal mensal e nível de escolaridade.

O questionário foi submetido a um pré-teste, o que permitiu melhorar a redação e a compreensão das perguntas por parte dos respondentes. Particular atenção foi dada ao tempo de aplicação do questionário de forma a não exceder a 15 minutos por respondente.

\section{RESULTADOS E DISCUSSÃO}

Nesta seção, primeiramente, apresenta-se a descrição do perfil dos respondentes em termos de suas características demográficas, socioeconômicas e suas atitudes com 
relação ao desenvolvimento da energia eólica. Em seguida, faz-se a análise e discussão dos modelos de formação de atitude, particularmente sobre a significância e direção dos efeitos marginais das variáveis explicativas sobre a posição de apoiar ou não a política de desenvolvimento da energia eólica no litoral cearense.

\subsection{PERFIL DOS RESPONDENTES}

$\mathrm{Na}$ Tabela 2 se apresenta a média e o percentual das variáveis para o total da amostra e das subamostras de Canoa Quebrada e Jericoacoara. Nesta tabela, são também apresentados os resultados dos testes de comparação de médias (teste $t$ de Student) e proporções (teste qui-quadrado e binomial) das variáveis contínuas e categóricas para as duas localidades, tendo como hipótese nula a igualdade das estimativas dos parâmetros.

Os testes de comparação de médias e proporções demonstraram que, para a grande maioria das variáveis, as estimativas dos parâmetros foram estatisticamente iguais entre as duas localidades. Apenas seis variáveis apresentaram diferenças significativas: a renda pessoal mensal nas faixas inferior a $\mathrm{R} \$ 2.400$ e de $\mathrm{R} \$ 2.400$ a $\mathrm{R} \$$ 8.000; o nível de escolaridade; e os dias de permanência na praia, particularmente no período igual ou maior que seis dias; e percepção de poluição sonora causada pelas turbinas eólicas.

Portanto, dado a similaridade entre a maioria das estimativas dos parâmetros, é provável que as subamostras tenham sido originadas de uma população de turistas relativamente homogênea. Por esta razão, as duas amostras foram reunidas e tratadas como uma amostra única.

TABELA 2 - MÉDIA E PERCENTUAL DAS RESPOSTAS DO TURISTA DOMÉSTICO DISTRIBUÍDAS POR DESTINO DE PRAIA E AMOSTRA TOTAL

\begin{tabular}{llccc}
\multicolumn{1}{c}{ Variáveis } & \multicolumn{1}{c}{ Definição } & $\begin{array}{c}\text { Canoa } \\
\text { Quebrada }\end{array}$ & Jericoacoara & Total \\
\hline Posição política & Respostas favoráveis (\%) & 76,9 & 65,4 & 71,8 \\
Idade & Média de idade dos respondentes (anos) & 35,6 & 34,5 & 35,1 \\
Gênero & Feminino (\%) & 50,8 & 63,5 & 56,4 \\
Estado civil & Solteiros (\%) & 58.5 & 57,7 & 58.1 \\
Número de filhos & Sem filhos (\%) & 61,5 & 61,5 & 61,5 \\
& & & & $39.3 * *$ \\
Renda média & Até R\$ 2.400 (\%) & 47.7 & 28,8 & $44.4 *$ \\
mensal & De R\$ 2400 a R\$ 8.000 (\%) & 36.9 & 53,8 & 16.2
\end{tabular}




\begin{tabular}{|c|c|c|c|c|}
\hline \multirow{2}{*}{ Escolaridade } & $\begin{array}{l}\text { Analfabeto e nível fundamental ou médio, } \\
\text { completo ou incompleto }(\%)\end{array}$ & 41,5 & 25,0 & \\
\hline & $\begin{array}{l}\text { Nível superior ou pós-graduação, completo } \\
\text { ou incompleto }(\%)\end{array}$ & 58,5 & 75,0 & $65,8^{*}$ \\
\hline $\begin{array}{l}\text { Frequência de } \\
\text { visitas à praia }\end{array}$ & Raramente ou de vez em quando (\%) & 61,5 & 53,8 & 58.1 \\
\hline \multirow{3}{*}{$\begin{array}{l}\text { Permanência na } \\
\text { praia }\end{array}$} & Um ou dois dias $(\%)$ & 44.6 & 30,8 & 38.5 \\
\hline & De três a cinco dias $(\%)$ & 47.7 & 34,6 & 41.9 \\
\hline & Seis dias ou mais dias $(\%)$ & 7.7 & 34,6 & $19.6^{* * * *}$ \\
\hline \multirow{5}{*}{$\begin{array}{l}\text { Atitude com } \\
\text { relação ao } \\
\text { desenvolvimento } \\
\text { da energia eólica } \\
\text { na zona costeira } \\
\text { (média) }\end{array}$} & Usina eólica é fonte de energia limpa & 3,4 & 3,4 & 3,4 \\
\hline & Prefiro paisagem com usina eólica & 2,6 & 2,5 & 2,6 \\
\hline & Usina eólica é atrativo turístico & 2,5 & 2,6 & 2,5 \\
\hline & $\begin{array}{l}\text { Prefiro perder paisagem do que ficar sem } \\
\text { energia elétrica }\end{array}$ & 2,6 & 2,6 & 2,6 \\
\hline & $\begin{array}{l}\text { Comunidades afetadas pelas usinas eólicas } \\
\text { não devem ser compensadas }\end{array}$ & 1,9 & 2,1 & 1,9 \\
\hline \multirow{6}{*}{$\begin{array}{l}\text { Percepção do } \\
\text { Impacto } \\
\text { socioambiental } \\
\text { (média) }\end{array}$} & Obstrução da vista & 2,6 & 2,8 & 2,6 \\
\hline & Poluição visual & 2,4 & 2,7 & 2,5 \\
\hline & Poluição sonora & 1,8 & 2,7 & $2,2 * * *$ \\
\hline & Morte acidental de pássaros por colisão & 3,3 & 3,2 & 3,2 \\
\hline & Migração das dunas & 2,9 & 2,6 & 2,8 \\
\hline & Restrição de acesso às comunidades & 3,0 & 2,8 & 2,9 \\
\hline IDEE & $\begin{array}{l}\text { Índice médio de desenvolvimento da energia } \\
\text { eólica por indivíduo }\end{array}$ & 2,8 & 2,8 & 2,8 \\
\hline IISA & $\begin{array}{l}\text { Índice médio de percepção de impacto } \\
\text { socioambiental }\end{array}$ & 2,6 & 2,8 & 2,7 \\
\hline Total da Amostra & Total de respondentes entrevistados por praia & 52 & 65 & 117 \\
\hline
\end{tabular}

Nota: (*) significa $\mathrm{P}<0,10 ;(* *)$ significa $\mathrm{P}<0,05$; e $(* * *)$ significa $\mathrm{P}<0,01$;

Fonte: Dados da Pesquisa.

Considerando o número total de respondentes, constatou-se que a maioria dos turistas foi a favor do desenvolvimento da energia eólica na zona costeira, correspondendo a 71,8\% da amostra. O perfil típico do turista esteve caracterizado por ter a média da idade em torno de 35 anos, ser do sexo feminino, solteira e sem filhos. Possuindo média de renda pessoal mensal no intervalo entre $R \$ 2.400$ e $R \$ 8.000$ e nível de escolaridade superior ou pós-graduado. Porém, os percentuais se diferenciaram entre Canoa Quebrada e Jericoacoara, esta última atraindo turistas com renda e escolaridade relativamente maiores. Seu comportamento de visitar a praia demonstrouse ser pouco frequente (raramente ou de vez em quando) e sua permanência na praia ficando em torno de 3 a 5 dias. Entretanto, Jericoacoara apareceu como um destino 
preferido por um percentual maior de turistas quando a permanência pretendida se referia a de seis dias ou mais.

A média de aprovação com relação aos fatores que afetavam o desenvolvimento da energia eólica variou entre 2,5 a 3,4 (em uma escala de 1 a 4), sendo sua convicção mais fortemente expressa para a afirmação de que a energia eólica seria a de uma fonte de energia limpa $(3,4)$. Os escores médios relativos atribuídos pelos respondentes quanto à percepção dos impactos causados pelas usinas eólicas ficaram em níveis moderados, variando entre 2,2 e 3,2 (em uma escala de 1 a 5). Apenas a poluição sonora mostrou-se estatisticamente diferente em termos de escores entre os destinos, tendo sido percebido pelos turistas como baixo em Canoa Quebrada e moderado em Jericoacoara. Tal diferença pode ter sido determinada pelo nível de informação quando ao impacto considerado. Em princípio, em Canoa Quebrada, o turista tendo uma experiência direta com as turbinas eólicas, o que não se observou em Jericoacoara.

A expressão média da atitude política e da percepção dos impactos socioambientais da energia eólica é expressa pelas variáveis IDEE e IISA. Em termos médios, o IDEE demonstrou que os turistas eram favoráveis ao desenvolvimento da energia eólica, tendo obtido valor médio de 2,8 , em uma escala de 1 a 4 . O IISA demonstrou que os turistas tinham percepção dos impactos socioambientais em níveis moderados, já que o valor médio foi de 2,7 em uma escala de 1 a 5 .

\subsection{ANÁLISE DOS MODELOS DE FORMAÇÃO DE ATITUDES}

Os seis modelos logit estimados obtiveram pseudo $\mathrm{R}^{2}$ variando no intervalo de $21,2 \%$ a $32,7 \%$, portanto, apresentando baixo grau de ajustamento dos dados primários (Tabela 3). Esse baixo desempenho é comumente observado em estudos que tratam de modelos de formação de atitudes em virtude da complexidade e dificuldade de descrever o comportamento e as atitudes das pessoas com relação a uma questão.

TABELA 3 - MODELOS LOGIT DA FORMAÇÃO DE ATITUDE COM RELAÇÃO AO DESENVOLVIMENTO DA ENERGIA EÓLICA NA ZONA COSTEIRA DO CEARÁ

\begin{tabular}{lcccccc}
\hline & ML1 & ML2 & ML3 & ML4 & ML5 & ML6 \\
& Coef. & Coef. & Coef. & Coef. & Coef. & Coef. \\
\hline XIDADE & 0,030 & & 0,043 & 0,044 & 0,021 & 0,035 \\
XGENERO & $-1,179^{*}$ & & $-1,009^{*}$ & $-0,895$ & $-1,115^{*}$ & $-0,939$
\end{tabular}




\begin{tabular}{|c|c|c|c|c|c|c|}
\hline XESTCIV & 0,772 & & 0,654 & 0,782 & 0,472 & 0,651 \\
\hline XNFILHOS & 0.173 & & 0,271 & 0,183 & 0,068 & 0,215 \\
\hline XRENDA1 & 1,057 & & 1,324 & 0,927 & 0,545 & 1,086 \\
\hline XRENDA2 & $2,292 * *$ & & $2,182 * * *$ & $2,150 * *$ & $1,680^{* *}$ & $1,891 * *$ \\
\hline XESCAMF & $-1,193$ & & $-0,654$ & $-0,681$ & $-0,774$ & $-1,037^{*}$ \\
\hline YPRAIA & 1,193 & 0,902 & & 0,948 & 0,930 & 0,578 \\
\hline YFQPRAIA & 0,693 & 0,443 & & 0,706 & 0,580 & 0,707 \\
\hline YPERM12 & $-0,106$ & $-0,374$ & & $-0,456$ & 0,279 & 0,408 \\
\hline YPERM35 & 0,482 & $-0,132$ & & 0,150 & 0,449 & 0,695 \\
\hline WENGLIMPA & 0,422 & 0,147 & 0,450 & & $0,765^{*}$ & \\
\hline WPSGEOLIC & 0,129 & 0,248 & 0,294 & & $0,606^{*}$ & \\
\hline WEOLICAT & 0,504 & 0,428 & 0,305 & & $0,787^{* *}$ & \\
\hline WPREFEO & 0,200 & 0,016 & 0,113 & & 0,108 & \\
\hline WСОМРСОМ & 0,068 & $-0,213$ & $-0,119$ & & 0,005 & \\
\hline ZOBSTPGS & 0,053 & $-0,035$ & $-0,030$ & $-0,020$ & & \\
\hline ZPOLVIS & $-0,509$ & $-0,324$ & $-0,452$ & $-0,625^{*}$ & & \\
\hline ZPOLSON & 0,078 & 0,085 & $-0,015$ & 0,035 & & \\
\hline ZMTACIDENT & 0,223 & $-0,001$ & 0,180 & 0,339 & & \\
\hline ZMIGDUNA & $-0,592^{*}$ & $-0,453^{*}$ & $-0,445$ & $-0,653 * *$ & & \\
\hline ZRESTACES & $-0,050$ & 0,045 & $-0,006$ & $-0,146$ & & \\
\hline$I D E E$ & & & & & & $1,773^{* *}$ \\
\hline IISA & & & & & & $-0,864 * * *$ \\
\hline _cons & $-3,074$ & $-0,394$ & $-3,154$ & 0,503 & $-7,334 * *$ & $-4,560 * * *$ \\
\hline N. & 117 & 117 & 117 & 117 & 117 & 117 \\
\hline Pseudo $\mathrm{R}^{2}$ & 32,7 & 21,2 & 28,0 & 30,0 & 24,2 & 28,0 \\
\hline $\mathrm{R}^{2}$ de Contagem & 82,1 & 76,9 & 79,5 & 81,2 & 79,5 & 83,8 \\
\hline $\operatorname{TRV}\left(\mathrm{P}>\chi^{2}\right)$ & & $\begin{array}{l}15,9 \\
\left(0,026^{* *}\right)\end{array}$ & $\begin{array}{l}6,3 \\
(0,164)\end{array}$ & $\begin{array}{l}3,8 \\
(0,568)\end{array}$ & $\begin{array}{l}11,8 \\
(0,066 * *)\end{array}$ & \\
\hline
\end{tabular}

Nota: $(*)$ significa $\mathrm{P}<0,10 ;(* *)$ significa $\mathrm{P}<0,05$; e $(* * *)$ significa $\mathrm{P}<0,01$; Fonte: Dados da Pesquisa.

Os dois modelos em que melhor os dados se ajustaram foram ML1 e ML4, obtendo 32,7\% e 30\%, respectivamente. O ML1 corresponde ao modelo logit expandido, ou seja, considerando todas as variáveis explicativas e o ML4 é um modelo restrito que foi obtido através da exclusão do conjunto de variáveis que retratam a atitude política dos respondentes. Observa-se que a exclusão desse conjunto de variáveis causou apenas uma pequena redução no poder explicativo do modelo, o que revela a baixa importância das atitudes políticas dos respondentes em explicar seu posicionamento com relação a política em questão. Esta conclusão é apoiada pelo resultado do teste da razão de verossimilhança (TRV) que comparou o ML4 ao ML1. 
Os dois modelos que tiveram a maior redução no desempenho em ajustar os dados foram ML2 e ML5, obtendo 21,2\% e 24,2\%, os quais foram estimados excluindo as características demográficas dos respondentes e os fatores de impactos socioeconômicos, respectivamente. Isto demonstra que a exclusão dessas variáveis reduz fortemente o poder explicativo desses modelos. Este resultado é corroborado pelo TRV que se mostrou significativo para ambos, ML2 e ML5, tendo como base o ML1.

Já os modelos ML3 e ML4 obtidos pela exclusão das variáveis que descrevem a experiência recreativa e as atitudes políticas dos respondentes, respectivamente, não obtiveram uma redução significativa no seu poder explicativo (28\% e $30 \%)$ quando comparados ao ML1. Este resultado ficou estatisticamente demonstrado através do TRV ao comparar os modelos ML3 e ML4 com o modelo base, ML1.

O ML6 que é estimado substituindo o conjunto de variáveis que descrevem a atitude política e o impacto socioeconômico pelos seus respectivos índices compostos experimentou uma ligeira redução no desempenho do modelo $(28 \%)$ em ajustar os dados, posicionando-o entre os modelos com desempenho mediano (ML3 e ML4).

\subsection{ANÁLISE DOS COEFICIENTES}

As variáveis explicativas demográficas que se mostraram significantes em pelo menos um modelo foram: gênero (ML1, ML3 e ML6), renda na faixa de R \$ 2.400-R \$ 8.000 (ML1, ML3, ML4, ML5 e ML6), e escolaridade até nível médio ou analfabeto (ML6). As variáveis que descrevem a experiência de recreação não se mostraram significativas em nenhum dos modelos. Três variáveis que descrevem a atitude política dos turistas mostraram-se significativas em apenas um modelo, ML5, são elas: energia limpa (WENGLIMPA), paisagem com turbinas eólicas (WPSGEOLIC) e usina como atrativo turístico (WEOLICAT). Duas variáveis que descrevem a percepção dos impactos socioambientais mostraram-se significativas apenas no modelo ML4: poluição visual (ZPOLVIS) e migração de dunas. (ZMIGDUNA) Os índices compostos das atitudes políticas e da percepção dos impactos se mostraram significativos no único modelo em que foram testadas, ML6.

O gênero do respondente afetou significativamente sua posição política quanto a apoiar ou não o desenvolvimento da energia eólica na zona costeira. O coeficiente da 
variável XGENERO assumiu valor negativo, significando que pelo fato do respondente ser do sexo feminino a probabilidade de apoiar a política diminui comparada ao do sexo masculino. Desta forma, os turistas do sexo masculino estiveram mais inclinados a apoiar o desenvolvimento da energia eólica. Este fato foi demonstrado nos seis modelos estimados, porém somente demonstrou significância nos modelos ML1, ML3 e ML5.

O nível de renda do turista também afetou significativamente sua disposição a apoiar a política de energia eólica, das quais somente a variável XRENDA2 se mostrou significativa em todos os modelos onde foi testada pelo menos ao nível de $5 \%$ de significância. Sendo o coeficiente desta variável positiva, os turistas na faixa de renda $\mathrm{R} \$ 2.400$ - R\$ 8.000 contribuíram para aumentar o apoio à política de energia eólica se comparado aos outros níveis de renda. Embora a variável XRENDA1 não tenha se mostrado significativa, seu coeficiente também foi positivo, porém com valor relativamente menor.

O nível educacional se mostrou significante apenas no ML6, em que as variáveis de atitude política e percepção de impacto foram substituídas por seus respectivos índices compostos. Nos demais modelos, mesmo sendo insignificante, a variável escolaridade mais inferior (XESCAMF) se mostrou consistente em termos de sinal, tendo este obtido valor negativo. Isto significa que os turistas com menor nível de escolaridade - Analfabeto, Ensino Fundamental e Médio - se mostraram menos inclinados a apoiar a política de energia eólica se comparado aos turistas com nível de escolaridade maior - nível superior e pós-graduado.

A variável destino de praia dos turistas, YPRAI, não se mostrou significativa em nenhum dos modelos. Apesar disso, esta variável se mostrou consistente em termos de sinal, tendo assumido valor positivo em todos os modelos. Pelo fato da variável dummy ter como referência os turistas da praia de Jericoacoara, os coeficientes revelaram que os turistas da praia de Canoa Quebrada estavam mais inclinados a apoiar a política de energia eólica. Isto pode ser determinado pelo fato dos turistas já estarem convivendo com as alterações na paisagem ocasionadas pelas usinas eólicas existentes na Canoa Quebrada enquanto em Jericoacoara este tipo de intervenção ainda era inexistente.

A variável frequência de visita a praia, YFQPRAIA, também não se mostrou significante nos modelos estimados. Apesar disso, esta variável obteve valor positivo em todos os modelos, significando que os turistas mesmo visitando a praia raramente ou 
de vez em quanto ainda assim estavam dispostos a apoiar a política de energia eólica se comparado aos turistas que visitavam a praia frequentemente. Este resultado pode sugerir que a frequência de visitas a praia não seja um fator relevante na formação da atitude do turista com relação ao desenvolvimento da energia eólica no litoral cearense.

As variáveis que controlam pelo número de dias de permanência na praia, YPERM12 e YPERM35, apresentaram coeficientes insignificantes e ambiguidade quanto aos seus sinais, podendo assumir valores positivo ou negativo. Portanto, os resultados não permitiram definir direção do efeito marginal dessas variáveis explicativas na posição política dos turistas.

Em geral, as variáveis que descrevem a atitude política dos turistas com relação ao desenvolvimento da energia eólica não demonstraram significância nos modelos estimados. Apenas um modelo, ML5, apresentou variáveis significativas nesta categoria: energia eólica é fonte de energia limpa (WENGLIMPA), prefiro paisagem com energia eólica (WPSGEOLIC), e usina eólica é mais um atrativo turístico (WEOLICAT). Os coeficientes dessas variáveis apresentaram coeficientes positivos, significando que quanto mais os turistas concordaram com essas afirmações, maior sua disposição de apoiar a política de energia eólica. Dentre essas afirmações, apenas a variável WCOMPCOM obteve coeficiente com sinal negativo (ML2 e ML3), significando que deixar de compensar as comunidades afetadas faz diminuir a probabilidade dos turistas apoiarem uma política de energia eólica. Em outras palavras, os turistas demonstraram preocupação com as questões de equidade relacionadas à política de energia eólica.

Dentre as variáveis que descrevem a percepção dos impactos socioambientais, apenas duas se mostraram significativas em pelo menos um modelo de formação de atitude política dos turistas. Essas variáveis foram: poluição visual (ZPOLVIS) no ML4 e migração de dunas (ZMIGDUNA) no ML1, ML2 e ML4. Essas variáveis obtiveram coeficiente com valor negativo, mesmo naqueles modelos onde foram insignificantes. Isto significa que quanto maior os impactos negativos das usinas eólicas sobre a paisagem e as dunas, menos inclinadas eles estiveram em apoiar a política de energia eólica. Os coeficientes dos demais impactos, além de insignificantes, tiveram sinais positivos e negativos nos modelos, portanto, indefinidos quando a direção do efeito marginal sobre a posição política dos turistas. 
Pode-se observar que as variáveis de atitude política e percepção de impactos ficaram correlacionadas, ou seja, a percepção dos impactos poderia ter influenciado a atitude política dos turistas. Por exemplo, se o turista percebe a poluição visual como uma externalidade negativa relevante para sua experiência turística ou recreativa, ele pode manifestar uma atitude contrária ao desenvolvimento da energia eólica. Portanto, as variáveis de atitude política e percepção dos impactos podem ter sido afetadas pelo problema de multicolinearidade.

Para verificar tal problema, O ML4 testa a exclusão das variáveis de atitude política e o ML5 testa a exclusão das variáveis de percepção dos impactos ambientais. O que se observa é que quando essas categorias são consideradas separadamente nos modelos, algumas das variáveis tornaram-se significantes para explicar a posição política dos turistas.

Os indicadores compostos que expressam a atitude política dos turistas (IDEE) e a percepção dos impactos socioambientais (IISA) mostraram-se significantes no único modelo em que foram testadas (ML6). O IDEE obteve coeficiente positivo e significante ao nível de 5\%, indicando que quanto maior o grau de aceitação dos descritores de atitude política, maior a disposição dos entrevistados em apoiar a política de energia eólica. Esta pode ser uma evidência de que o grau de apoio dos turistas à política de energia eólica dependeu da crença de quão próxima esta política estaria das metas de sustentabilidade ambiental.

O IISA obteve coeficiente negativo e significativo ao nível de $1 \%$, significando que quando maior o impacto socioambiental percebido pelo turista, menor sua intenção de apoiar a política de energia eólica. Este resultado esteve de acordo com a intuição de que quanto maiores os impactos socioambientais de uma política, menos inclinados eles estariam em apoiar tal política. Esta relação negativa revelou que a probabilidade de apoio dos turistas à política de energia eólica dependeu do nível de impacto socioambiental percebido pelos turistas.

\section{CONCLUSÕES E SUGESTÕES}

A atitude política do turista doméstico estava direcionada a apoiar a política de energia eólica no litoral cearense. Os modelos logit de formação de atitudes permitiram 
concluir que as variáveis demográficas e a percepção dos impactos socioambientais das usinas eólicas tiveram maior efeito sobre a posição política dos turistas. Dentre as variáveis analisadas, foram estatisticamente significativas as variáveis de gênero, a faixa de renda pessoal mensal entre $R \$ 2400$ - $R \$ 8000$ e escolaridade de nível médio ou inferior. A probabilidade de o turista apoiar a política de energia eólica aumentou quanto maior foi sua convicção sobre a natureza da fonte de energia (energia limpa), aceitação de alteração da paisagem pelas turbinas eólicas e possibilidade das usinas eólicas serem mais um atrativo turístico na zona costeira. Por outro lado, a probabilidade reduziu quanto maior foi a convicção do turista sobre a poluição visual e migração de dunas. Constatou-se que os índices compostos das atitudes políticas e percepção dos impactos se mostraram significativos em explicar a posição política dos turistas podendo ser utilizados em substituição às variáveis explicativas relacionadas.

Esclareça-se que nesta pesquisa se investigou apenas um elo da cadeia do turismo, o turista doméstico, e a maioria destes se mostrou favorável ao desenvolvimento da energia eólica na zona costeira cearense. Observou-se também que o grau de aceitação da política de energia eólica pelos turistas ficou determinado pelo gênero, nível de educação e renda, e sua atitude política e percepção dos impactos socioambientais. Isto sugere que o nível de informação para os visitantes e/ou usuários das praias na zona costeira pode influenciar o grau de aceitação da política de energia eólica. Sugere-se também que a política de energia eólica incorpore em seu planejamento etapas que contemplem aspectos relacionados à educação ambiental e esclarecimentos sobre os impactos socioambientais da energia eólica para os atores sociais diretamente afetados pela política.

\section{REFERÊNCIAS}

ALVES J. Análise Regional da Energia Eólica no Brasil. Revista Brasileira de Gestão e Desenvolvimento Regional, v. 6, n. 1, p. 165-188, Taubaté, SP, Brasil, jan.-abr./2010.

AMARAnte, O. A. C.; BROWER, M.; ZACK, J.; SÁ, A. L. Atlas do Potencial Eólico Brasileiro. Brasília: MME, Rio de Janeiro: Eletrobrás, 2001. Disponível em: $<$ http://www.cresesb.cepel.br/publicacoes/download/atlas_eolico/Atlas\%20do\%20Poten cial\%20Eolico\%20Brasileiro.pdf>. Acesso em: 27/01/2014. 
ANEEL. Atlas de Energia Elétrica do Brasil. ANEEL, 2008. Disponível em: $<$ http://www.cresesb.cepel.br/publicacoes/download/atlas_eolico/Atlas\%20do\%20Poten cial\%20Eolico\%20Brasileiro.pdf >. Acesso em: 28/03/2013.

Banco de Informação de Geração (BIG): Usina do tipo eólica em operação. Agência Nacional de Energia Elétrica, 2014. Disponível em: <http://www.aneel.gov.br/aplicacoes/capacidadebrasil/OperacaoGeracaoTipo.asp?tipo= 7\&ger=Outros\&principal=E\%C3\%B3lica $>$. Acesso em: 30/01/2014.

BRASIL. Destino de Referência em Turismo de Sol e Praia: Jericoacoara-CE. Ministério do Turismo, Instituto Casa Brasil de Cultura, 2010.

DEMARIS, A. Logit Modeling: Practical Applications. Sage University Paper series on Quantitative Applications in the Social Sciences, 07-086. Newbury Park, CA: Sage, 1992.

EK, K. Public and Private Attitudes towards Green Electricity: the case of Swedish wind power. Energy Policy, v. 33, p. 1677-89, 2005.

EPE (2011). Plano Decanal de Expansão de Energia 2020. Empresa de Pesquisa Energética, 2011. Disponível em:

<http://www.mme.gov.br/mme/galerias/arquivos/noticias/2011/RELATxRIO_PDE_202 0.pdf>. Acesso em: 29/01/2014.

GUJARATI, D. N. Basic Econometrics. 4 ed. New York: McGraw Hill, 2003.

JONES, C. R.; EISER J. R. Understanding 'Local' Opposition to Wind Development in the UK: How Big is a Back Yard? Energy Policy, v. 38, p. 3106-17, 2010.

KARYDIS, M. Public Attitudes and Environment Impacts of Wind Farms: a Review. Global NEST Journal, v. 15, n. 4, p. 581-600, 2013.

KROHN, S.; DAMBORG, S. On Public Attitudes Towards Wind Power. Renewable Energy, v. 16, p. 954-60, 1999.

KRUEGER, A. D.; PARSONS, G. R.; FIRESTONE, J. Valuing the Visual Disamenity of Offshore Wind Projects at Varying Distances from the Shore. Land Economics, v. 87 (2), p. 268-283, mai.de 2011.

LADENBURG, J. Attitudes Towards On-Land and Offshore Wind Power Development in Denmark: Choice of Development Strategy. Renewable Energy, v. 33, p. 111-118, 2008.

Attitudes Towards Offshore Wind Farms - The Role of Beach Visits on Attitude and Demographic and Attitude Relations. Energy Policy, v. 38, p. 1297-1304, 2010. 
LADENBURG, J; MÖLLERB, B. Attitude and Acceptance of Offshore Wind Farms The Influence of Travel Time and Wind Farm Attributes. Renewable and Sustainable Energy Reviews, v. 15, p. 4223-4235, 2011.

MEYERHOFF, J.; OHL, C.; HARTJE, V. Landscape Externalities from Onshore Wind Power. Energy Policy, v. 38, p. 82-92, 2010.

MOURA-FÉ, M. M.; PINHEIRO, M. V. A. Os Parques Eólicos na Zona Costeira do Ceará e os Impactos Ambientais Associados. Revista Geonorte, v. 9, n. 1, p. 22-41, 2013.

NASCIMENTO, T. C.; MENDONÇA, A. T. B. B.; CUNHA, S. K. Inovação e sustentabilidade na produção de energia: o caso do sistema setorial de energia eólica no Brasil. Cardenos EBAPE.BR, v. 10, n. 3, p. 630-651, 2012.

CEARÁ. Evolução Recente do Turismo no Ceará. Fortaleza: SETUR (CE), 2 ed., Estudos Turísticos da SETUR, n. 17, 2006.

Evolução Recente do Turismo no Ceará. Fortaleza: SETUR (CE), 4 ed., Estudos Turísticos da SETUR, n. 17, 2009.

SIMAS, M.; PACCA, S. Energia eólica, geração de empregos e desenvolvimento sustentável. Estudos Avançados, v. 27, n. 77, p. 99-115, 2013 a.

SOUZA NETO, G. F. O Estado em Ação: Produção Espacial pelas Políticas de Turismo em Aracati/CE. Mestrado Acadêmico em Geografia, Universidade Estadual do Ceará, 2011. (Dissertação)

Socio-economic Benefits of Wind Power in Brazil.

Journal of Sustainable Development of Energy, Water and Environment Systems, v. 1, n. 1, p. 27-40, 2013b. Disponível em:

<http://dx.doi.org/10.13044/j.sdewes.2013.01.0003>. Acesso em: 29/01/2014.

SNYDER, B.; KAISER, M. Ecological and Economic Cost-Benefit Analysis of Offshore Wind Energy. Renewable Energy, v. 34, p. 1567-1578, 2009.

WOOLDRIDGE, J. M. Introductory Econometrics: A Modern Approach. 3 ed. Mason, OH: Thomson/South-Western, 2006.

Recebido em: 06-02-2014.

Aprovado em: 04-03-2014. 